\begin{tabular}{|c|c|}
\hline Title & Effect of Helium and A ging Treatment on Radiation Damage Behavior in Low A ctivation Fe-Cr-Mn (W, V) Alloy \\
\hline Author(s) & Kinoshita, H.; Hu, Benfu; Takahashi, H. \\
\hline Citation & $\begin{array}{l}\text { PRICM-5: Proceedings of the 5th Pacific Rim International Conference on A dvanced Materials and Processing, Pts 1-5, } \\
\text { 1455-1458 }\end{array}$ \\
\hline Issue Date & 2005 \\
\hline Doc URL & http:/hdl.handle.net/2115/16903 \\
\hline Rights & the original is available online at www.scientific.net \\
\hline Type & article (author version) \\
\hline Note & Materials Science Forum, V olume 475-479 \\
\hline File Information & PRICM5-1.pdf \\
\hline
\end{tabular}

Instructions for use 


\title{
Effect of Helium and Aging Treatment on Radiation Damage \\ Behavior in Low Activation Fe-Cr-Mn ( W, V) Alloy
}

\author{
H.Kinoshita ${ }^{1, a}$, Hu Benfu ${ }^{2, b}$ and H.Takahashi, ${ }^{1, c}$
}

${ }^{1}$ Fuculty of Engineering, Hokkaido University, Kita-13, Nishi-8, Kita-ku, Sapporo 060-8628 Japan

${ }^{2}$ Department of Materials Science and Engineering, University of Science and Technology

Beijing 100083 People's Republic of China

${ }^{3}$ Professor Emeritus of Hokkaido University, Kita-13, Nishi-8, Kita-ku, Sapporo 060-8628

Japan

a kinosita@ufml.caret.hokudai.ac.jp

b benfu@a-1.net.cn

c takahash@ufml.caret.hokudai.ac.jp

Keywords : low activation, Fe-Cr-Mn alloy, helium, electron irradiation, aging

\begin{abstract}
The effects of helium and aging treatment on radiation damage behavior in low activation Fe-Cr-Mn ( W, V) alloy were investigated by electron and helium ion dual-beam irradiation in a high voltage electron microscope. Specimens were aged at $673 \mathrm{~K}, 823 \mathrm{~K}$ and $923 \mathrm{~K}$ for 1000, 3000 and 10000 hours. Electron and He ion dual-beam irradiations were performed at $627 \mathrm{~K}$ to $10 \mathrm{dpa}$. $\mathrm{M}_{23} \mathrm{C}_{6}$ type carbides were precipitated in the aged specimens, and the amount of the precipitates was increased with increasing aging temperature and aging time. He bubbles were formed during dual-beam irradiation in all of the specimens. The cavity swelling under dual-beam irradiations was increased with increasing the aging temperature and aging time. It was suggested that cavity swelling is closely related to the concentration of solutes such as $\mathrm{Cr}$ and $\mathrm{C}$ in the matrix, namely cavity growth rate becomes higher with decreasing of the solutes in solution.
\end{abstract}

\section{Introduction}

Austenitic Fe-Cr-Mn alloys are noticed as one of lower activation materials in place of SUS316 austenitic stainless steels because of lower content of nickel element. Fe-Cr-Mn alloys modified with $\mathrm{W}$ and $\mathrm{V}$ elements have higher mechanical properties and irradiation damage resistance compared with Fe-Cr-Ni austenitic stainless steels [1,2]. During exposing to long-term flux irradiation of neutrons, defects are introduced in the matrix and helium atoms are also produced by transmutation reactions. Furthermore precipitates are nucleated and grow during irradiation as a result of aging. Thus cavity swelling and grain boundary brittleness are strongly influenced by existence of helium atoms [3,4,5]. It is not clear that the effect of helium and aging treatment on damage structure development such as phase stability, cavity swelling, precipitate formation and so on, in austenitic Fe-Cr-Mn low-activation alloys. The aim of this study is to examine the effect of helium atoms and aging treatment on irradiation damage structural development in a Fe-Cr-Mn (W,V) steel. Radiation experiments were performed using by electrons and helium ions in the High Voltage Electron Microscopy (JEM-ARM1300) connected with $300 \mathrm{keV}$ ion accelerator.

\section{Experimental procedures}


A Fe-Cr-Mn $(\mathrm{W}, \mathrm{V})$ alloy with excellent mechanical properties was used. Its chemical compositions (wt\%) are as follows: C: 0.26, Cr: 12.5, Mn: 15.6, Si: 0.25, Ni: 1.00, V: 0.94, W: 2.16, S: 0.0013, P: 0.001, N: 0.12. The alloy was prepared using high-purity raw materials and was melted in a vacuum induction furnace to reduce the impurities. The samples were heated at $1323 \mathrm{~K}$ for $5.4 \mathrm{ks}$ and aged at $673 \mathrm{~K}, 823 \mathrm{~K}$ and $923 \mathrm{~K}$ for 1000, 3000 and 10000 hours. The disk specimens were punched out with $0.2 \mathrm{~mm}$ in thickness and $3 \mathrm{~mm}$ in diameter for TEM observation and then were electro-jet polished. Electron and electron / He ion dual-beam irradiations were carried out in a HVEM (JEH-ARM1300) using a high-energy ions accelerator (300 keV). The electron irradiation conditions were $1.7 \times 10^{-3} \mathrm{dpa} / \mathrm{s}$ up to $10 \mathrm{dpa}$ at $673 \mathrm{~K}$. The helium injection rate was $70 \mathrm{atppm} / \mathrm{dpa}$ with accelerating voltage of $100 \mathrm{keV}$. The concentrations of solute elements after irradiation were analyzed by an energy dispersive x-ray spectroscopy (EDS) device.

\section{Results and discussion}

After solid solution treatment, the specimen exhibited austenite single phase. Fig.1 shows typical microstructures observed in aged specimens at 623, 823 and $923 \mathrm{~K}$ for 3000 hours. Precipitates were observed in the matrix and grain boundaries, and they were identified as carbides by EDS analysis. The amount of precipitates increased with increasing aging temperature. During electron single irradiation, fine cavities were nucleated with high number density only in the 923K-aged specimen. The cavity mean size and number density were $3.06 \mathrm{~nm}$ and $4.49 \times 10^{22} / \mathrm{m}^{2}$, respectively. In the case of electron / He ion dual-beam irradiation, He bubbles were formed in all specimens as indicated in Fig.2. The number density of cavities was lower and the mean size of cavities was larger than those of the electron single irradiation case (aged at $923 \mathrm{~K}$ ). The cavity mean size and number density measured in the specimens aged for 3000 hours irradiated with dual-beam were summarized in Table 1.
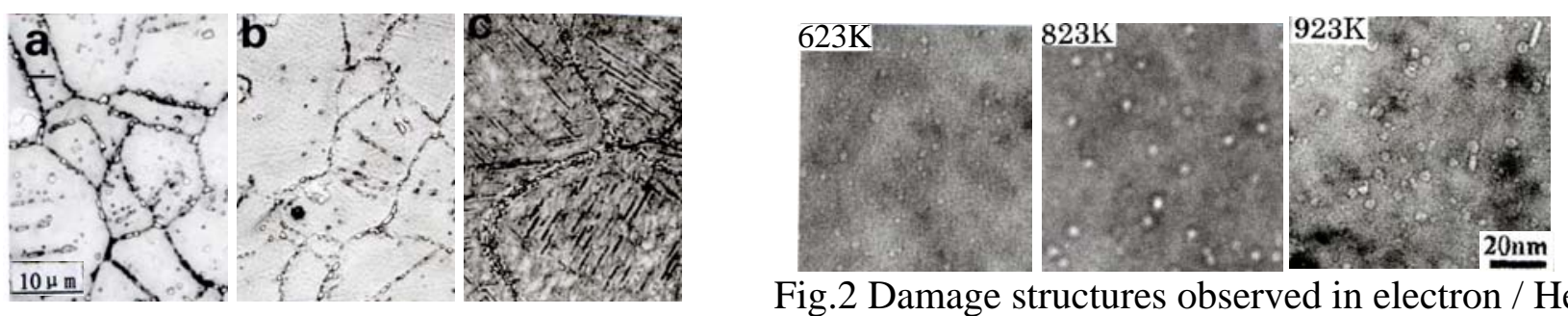

Fig.2 Damage structures observed in electron / He ion dual irradiated Fe-Cr-Mn (W, V) alloy at $673 \mathrm{~K}$ to $10 \mathrm{dpa}$. Specimens were aged at 623K, $823 \mathrm{~K}$ and 923K for 3000hr.

Table 1 The cavity mean size and number density of dual-beam irradiated at 673K to 10dpa..

$\begin{array}{lllcc}\text { Aging temperature } & \text { SST } & 623 \mathrm{~K} & 823 \mathrm{~K} & 923 \mathrm{~K} \\ \text { Cavity mean size }(\mathrm{nm}) & 2.4 & 3.1 & 3.3 & 3.2 \\ \text { Cavity number density }\left(\mathrm{N} / \mathrm{m}^{2}\right) & 2.5 \times 10^{22} & 2.7 \times 10^{22} & 1.0 \times 10^{23} & 3.1 \times 10^{22}\end{array}$

( SST: Solid Solution Treated specimen )

For dual-beam irradiated specimens, both of the void mean sizes and number densities of aged specimens were larger than those of the solid solution treated specimen. After irradiation grain boundary segregation was investigated by EDS analysis. $\mathrm{Cr}$ and Mn depletion and Fe enrichment were recognized in all irradiated specimens. The amount of solute segregation in dual-beam 
irradiated specimen was lower compared with electron single irradiation specimen. In the case of dual-beam irradiation, the cavity number density and cavity sink strength were higher than electron single irradiation case. The grain boundary segregation is influenced by dislocation density or structure. It might be said that grain boundary segregation is also influenced by cavity sink strength.

Fig.3 shows the irradiation dose dependence of the cavity mean size and number density measured in dual-beam irradiated specimens at $673 \mathrm{~K}$ to $10 \mathrm{dpa}$. The specimens were aged at $923 \mathrm{~K}$ for 1000, 3000 and 10000 hours before irradiation. For 10000 hours aged specimen, the cavity mean size was larger and the cavity number density was lower at 10 dpa comparing with 1000 and 3000 hours aged specimens. The cavity swelling of 1000, 3000 and 10000-aged specimens were $0.05,0.09$ and $0.31 \%$, respectively. It is clear that the longer the aging time, the higher the void swelling.
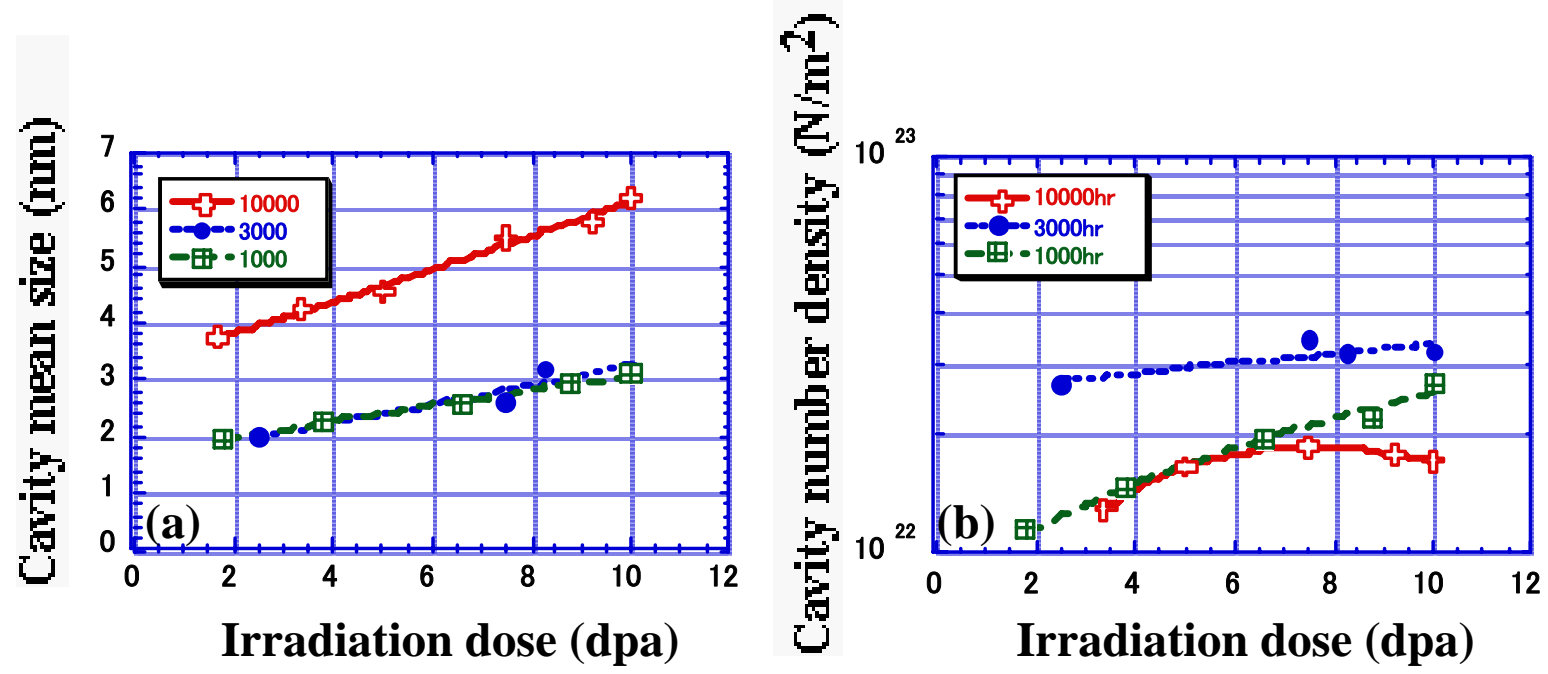

Fig.3 Irradiation dose dependence of the void mean size (a), and number density (b) measured in dual-beam irradiated specimens at $673 \mathrm{~K}$ to $10 \mathrm{dpa}$. Specimens were aged at $923 \mathrm{~K}$ for 1000, 3000 and 10000 hours before irradiation.

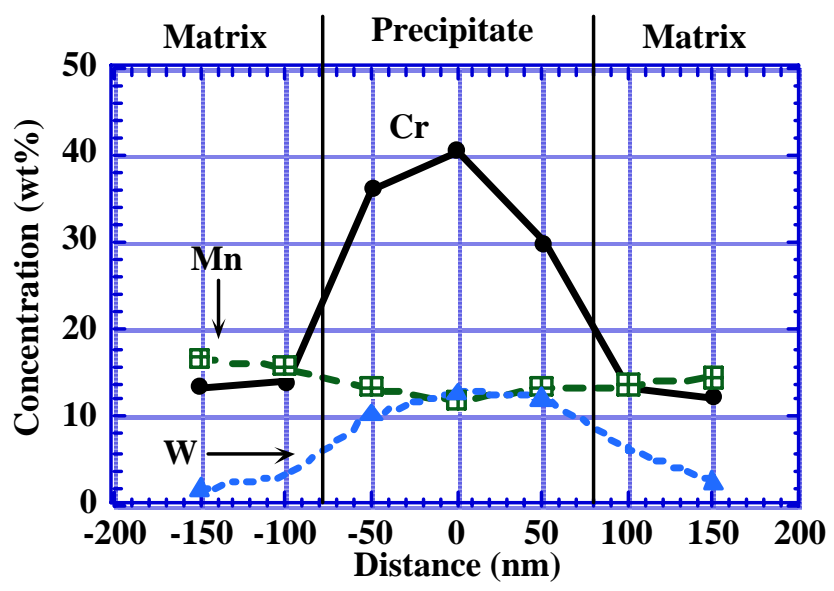

The cavity number density of 10000 hours aged specimen was decreased with increasing 
irradiation dose. This means the occurrence of cavity coalescence during irradiation. The results indicate that aging treatment enhances the cavity swelling. The reason why the cavity swelling was enhanced in long-term aged specimen is related to the amount of carbide precipitate formed during aging. Concentration profile of matrix and precipitate is shown in Fig.4.

In the precipitate region, $\mathrm{Cr}$ and $\mathrm{W}$ concentrations were increased, while $\mathrm{Cr}$ and $\mathrm{W}$ were depleted in the vicinity of precipitate. Compared to solid solution treated specimen and $923 \mathrm{~K}$-aged specimen (3000 hours), Cr, Mn, W and V elements of aged specimen were lower than those of non-aged specimen. These elements are over-sized elements compared to Fe matrix. Over-sized atom has trapping effect of vacancies, and they are effective for suppression of cavity formation. It is suggested that the depletion of these elements resulted in the enhancement of cavity growth and cavity swelling. To suppress the cavity swelling, existence of $\mathrm{Cr}, \mathrm{Mn}, \mathrm{W}$ and $\mathrm{V}$ elements is important. That is, due to long time and high temperature aging, the resistance of cavity swelling is reduced, because of reduction of elements in solution. When specimens were aged below 623K, a little amount of precipitate was formed, and the concentration of $\mathrm{Cr}$, $\mathrm{Mn}, \mathrm{W}$ and $\mathrm{V}$ element in the matrix was not depleted. From these results it is suggested that the desirable usage temperature of this specimen may be below $623 \mathrm{~K}$.

\section{Summary}

Electron single and electron / He ion dual-irradiation were performed in long time aged Fe-Cr-Mn (W, V) alloy. Results are as follows;

1. Carbide precipitates were formed in aged specimens. The amount of precipitates was increased with increased temperature of aging.

2. Voids were formed in only $923 \mathrm{~K}$ aged specimen by electron single irradiation.

3. In the case of dual-beam irradiation, He bubbles were formed in all specimens.

4. The cavity swelling observed in aged specimens was higher than that of solid solution treated specimen.

5. $\mathrm{Cr}, \mathrm{W}$ and $\mathrm{V}$ concentration in solution in the matrix decreased due to precipitate of carbides.

6. Depletion of $\mathrm{Cr}, \mathrm{W}$ and $\mathrm{V}$ in the matrix reduces the resistance of cavity swelling.

\section{References}

[1] H. Takahashi, Y. Shindo, H. Kinoshita,, Mechanical properties and damage behavior of non-magnetic high manganese austenitic steel, J. of Nucl. Mater., 258-263(1988) 1644-1650.

[2] Hu Benfu, H. Takahashi, Behaviors of Resistance to Irradiated Damage in Fe-Cr-Mn (W,V) Alloys with low Induced Radioactivity ,Chinese J. of Nucl. Sci. and Eng. Vol.17, No.2, Jun (1997) 143-149

[3] F. V. Nolfi Jr., A. Taylor and K. S. Grabowski, IEEE Trans. on Nucl. Sci., NS-26, (1979) 1257-1265

[4] W. J. Choyke, J. N. McGruer, J. R. Townsend, J. A. Spitznagel, N. J. Doyle and F. J. Venskytis , J. Nucl. Mater., 85 \& 86, (1979) 647-651

[5] Hu Benfu, Hiroshi Kinoshita, Tamaki Shibayama and Heishichiro Takahashi, Mater. Trans. JIM, Vol. 43, No.4 (2002) 622-626 